\title{
Effects of Atomoxetine on Height and Weight in Korean Children and Adolescents with Attention-Deficit/Hyperactivity Disorder: A Retrospective Chart Review
}

\author{
Kukju Kweon', Je Sik Yoon², Kee Jeong Park², Seon-Ok Kim³ ${ }^{3}$ Jin-Ho Choi ${ }^{4}$, and Hyo-Won Kim ${ }^{2}$ \\ ${ }^{1}$ Department of Psychiatry, University of Ulsan College of Medicine, Ulsan University Hospital, Ulsan, Republic of Korea \\ ${ }^{2}$ Department of Psychiatry, University of Ulsan College of Medicine, Asan Medical Center, Seoul, Republic of Korea \\ ${ }^{3}$ Department of Clinical Epidemiology and Biostatistics, Asan Medical Center, Seoul, Republic of Korea \\ ${ }^{4}$ Department of Pediatrics, University of Ulsan College of Medicine, Asan Medical Center Children's Hospital, Seoul, Republic of Korea
}

\begin{abstract}
Objective We aimed to investigate the long-term effects of atomoxetine on growth in Korean children and adolescents with attentiondeficit/hyperactivity disorder (ADHD).

Methods The medical records of 82 subjects (mean age, $9.0 \pm 2.0$ years; 64 boys) with ADHD treated with atomoxetine for at least 1 year at the Department of Psychiatry at Asan Medical Center were retrospectively reviewed. Height and weight data were prospectively obtained and retrospectively gathered and converted to age- and gender-corrected z scores using norms from Korean youths. Growth changes were analyzed using random coefficients models with changes in height or weight $\mathrm{z}$ scores as the dependent variables.

Results Height $\mathrm{z}$ scores significantly decreased during the treatment period $(\beta=-0.054, \mathrm{p}=0.024)$. Height $\mathrm{z}$ scores decreased during the 1 st year of treatment $(\beta=-0.086, p=0.003)$, but did not change after the 1st year. Weight $\mathrm{z}$ scores did not change significantly during treatment $(\beta=0.004, \mathrm{p}=0.925)$.

Conclusion Our results suggest that long-term atomoxetine treatment may be associated with deficits in height growth in Korean youths, although this effect was minor and tended to be attenuated over the first year. Because of the limitations of this study such as retrospective design and selection bias, further prospective studies are needed.

Psychiatry Investig 2018;15(6):649-654
\end{abstract}

Key Words Attention-deficit/hyperactivity disorder, Youth, Atomoxetine, Height, Weight.

\section{INTRODUCTION}

Atomoxetine is one of the most widely-used non-stimulant agent used for attention-deficit/hyperactivity disorder (ADHD). Atomoxetine has proven to be effective in clinical trials for reducing core ADHD symptoms and improving psychosocial functioning. ${ }^{1}$ Because ADHD often needs to be treated with medications for prolonged periods, clinicians and guardians of ADHD youths are particularly concerned about the adverse effects of medications, especially those leading to growth deficits.

Received: September 15, 2017 Revised: December 27, 2017

Accepted: February 25, 2018

$\triangle$ Correspondence: Hyo-Won Kim, MD, PhD

Department of Psychiatry, University of Ulsan College of Medicine, Asan Medical Center, 88 Olympic-ro 43-gil, Songpa-gu, Seoul 05505, Republic of Korea

Tel: +82-2-3010-3414, Fax: +82-2-485-8381, E-mail: shingubi@amc.seoul.kr

(a) This is an Open Access article distributed under the terms of the Creative Commons Attribution Non-Commercial License (http://creativecommons.org/licenses/bync/4.0) which permits unrestricted non-commercial use, distribution, and reproduction in any medium, provided the original work is properly cited.
Several long-term follow-up studies showed inconsistent results on the effects of atomoxetine on growth. Spencer et al. ${ }^{2,3}$ reported that there was a minimal deficit of height and weight growth of children and adolescents after atomoxetine treatment. Kratochvil et al. ${ }^{4}$ demonstrated that notable negative effects on growth of children aged 6 to 7 years were seen during the early phase of treatment and were attenuated afterwards at further follow-up. On the other hand, other studies reported no clinically significant effects on growth. ${ }^{5,6}$ However, there are only a few studies on the influence of atomoxetine long-term treatment on children's growth, especially compared to those of methylphenidate.

Moreover, most studies have been conducted in Western countries. It is known that atomoxetine is metabolized by cytochrome p450 2D6 (CYP2D6) and CYP2D6 poor metabolizers experience more adverse effects of atomoxetine, including growth deficits. Since there are significant ethnic differences in the prevalence of CYP2D6 poor metabolizer, ${ }^{8}$ and variants of CYP2D6 found in Asian population can change atomoxetine 
metabolism, ${ }^{9}$ there could be an interracial difference in the effects of atomoxetine on growth. Thus, we aimed to investigate the long-term effects of atomoxetine on growth in Korean children and adolescents with ADHD.

\section{METHODS}

We retrospectively reviewed the medical records of 82 children and adolescents with ADHD who were prescribed atomoxetine from May 2008 to September 2016 at the Department of Psychiatry at Asan Medical Center. All subjects had to meet the following inclusion criteria: 1) age of between 5 and 14 years at the start of atomoxetine treatment; 2) Diagnostic and Statistical Manual of Mental Disorders (DSM), Fifth Edition diagnosis of ADHD; 3) received treatment with atomoxetine for at least 1 year; and 4) baseline height and weight $\mathrm{z}$-scores greater than -2.0. This study was approved by the Institutional Review Board (IRB) of Asan Medical Center, and informed consent was waived by the board because of our retrospective study design. Some subjects of this study were participants for a prospective observational study in Asan Medical Center which enrolled ADHD outpatients aged 5 years or older. This study was approved by the IRB of Asan Medical Center and written informed consent was obtained from parents and written assent from participants for that study (IRB No. 2016-0448).

Subjects were excluded from the study if they had one or more of the following exclusion criteria: 1) prior exposure to atomoxetine; 2) prior exposure to methylphenidate for more than 1 year; 3) intelligent quotient (IQ) lower than 50; 4) past and/or current history of schizophrenia, bipolar disorder, or other psychosis; 5) presence of seizure disorder; 6) the mean compliance for the whole treatment period lower than $80 \%$; 7) combining medications which could affect growth (e.g., antipsychotics, mood stabilizers, and methylphenidate); and 8) past and/or current medical illness which could induce growth suppression.

All participants underwent general diagnostic and therapeutic procedures and a child psychiatrist monitored treatment. Measurements of height and weight were taken at every visit. Visits occurred at least every three months. Therefore, height and weight data were prospectively obtained and retrospectively gathered. Height and weight were converted to ageand gender-corrected $\mathrm{z}$ scores using norms from a '2007 Korean child and adolescent physical development standard value..10 A $\mathrm{z}$ score of 0 indicates that the measurement is at the mean of the population, whereas a $\mathrm{z}$ score of -1 or +1 indicates a measurement of one standard deviation less or more than the mean, respectively. Duration (years) and daily $\mathrm{mg} / \mathrm{kg}$ dose of atomoxetine were also gathered retrospectively from medical records. Because this study was as a retrospective design using medical records, missing data at various time points existed.

We analyzed growth from the start to the end of the treatment using a random coefficients model with changes in height and weight $\mathrm{z}$ scores from baseline ( $\Delta$ height and $\Delta$ weight $\mathrm{z}$ scores, respectively). We also examined whether the slopes of $\Delta$ height and $\Delta$ weight $\mathrm{z}$ scores differed between the time periods up to the 1st and beyond the 1st year of medication. The interactions between the $\Delta \mathrm{z}$ score and the following variables were examined with the univariate random coefficients model: age of first dose of atomoxetine, gender, baseline $\mathrm{z}$ score, ADHD type, mean daily $\mathrm{mg} / \mathrm{kg}$ dose, medication duration, and comorbid psychiatric disorders.

Statistical analyses were performed using SAS (version 9.2; SAS; Cary, NC, USA) and statistical significance was defined for all other comparisons at $p$ values of less than 0.05 . All comparisons were two-tailed.

\section{RESULTS}

\section{Demographic characteristics}

Between May 2008 and September 2016, a total of 583 youths with ADHD aged between 5 and 14 years were treated with atomoxetine. Among these subjects, 305 (52.4\%) were treated for less than one year. Reasons for discontinuation of atomoxetine were lack of efficacy $(56,18.4 \%)$, adverse events associated with gastrointestinal symptoms or growth $(42,13.8 \%)$, other adverse events $(66,21.6 \%)$, parental discretion $(12,3.9 \%)$, unknown due to missing data $(11,3.6 \%)$, and loss of followup $(118,38.7 \%)$. In addition, of the remaining 278 subjects, 196 were excluded according to exclusion criteria, most common cause was concomitant use of methylphenidate $(n=71$, $36.2 \%$ ), followed by comorbid epilepsy ( $n=55,28.1 \%)$, concomitant use of antipsychotics $(n=48,24.5 \%)$, other comorbid neurological disorders ( $n=36,18.4 \%$ ), and previous use of methylphenidate more than 1 year $(n=11,5.6 \%)$. Finally, 82 children and adolescents with ADHD were included in the analysis.

Demographics and clinical characteristics are detailed in Table 1. Of the 82 youths, 64 (78.0\%) were boys and the mean age of first dose was 9.0 \pm 2.0 years (range, $5.5-13.8$ years). Fortyfour subjects (53.7\%) had combined presentation, 31 (37.8\%) had predominantly inattentive presentation, one $(1.2 \%)$ had predominantly hyperactive-impulsive presentation, and six (7.3\%) was other specified ADHD.

Tic disorder was the most common comorbid psychiatric disorder ( $n=25,30.5 \%)$, followed by oppositional defiant/conduct (ODD/CD) $(n=17,20.7 \%)$, anxiety $(n=13,15.9 \%)$, autism spectrum disorder $(A S D)(n=6,7.3 \%), \operatorname{mood}(n=5,6.1 \%)$, obsessive compulsive (OCD) $(n=5,6.1 \%)$, and elimination 
Table 1. Demographic and clinical characteristics of subjects

\begin{tabular}{lc}
\hline & $\begin{array}{c}\text { Subjects } \\
(\mathrm{N}=82)\end{array}$ \\
\hline Age of first dose (yr), mean (SD) & $9.0(2.0)$ \\
Gender, boys, N (\%) & $64(78.0)$ \\
IQ, mean (SD) & $96.8(19.9)$ \\
Previous use of MPH less than 1 year, N (\%) & $14(17.1)$ \\
ADHD presentation, N (\%) & \\
Predominantly inattentive presentation & $31(37.8)$ \\
Predominantly hyperactive-impulsive presentation & $1(1.2)$ \\
Combined presentation & $44(53.7)$ \\
Other specified ADHD & $6(7.3)$ \\
Psychiatric comorbidities & \\
Tic disorder & $25(30.5)$ \\
ODD/CD & $17(20.7)$ \\
Anxiety disorder & $13(15.9)$ \\
ASD & $6(7.3)$ \\
Mood disorder & $5(6.1)$ \\
OCD & $5(6.1)$ \\
Elimination disorder & $3(3.7)$ \\
\hline ADD:
\end{tabular}

ADHD: attention-deficit/hyperactivity disorder, ASD: autism spectrum disorder, CD: conduct disorder, MPH: methylphenidate, OCD: obsessive compulsive disorder, ODD: oppositional defiant disorder, SD: standard deviation disorders $(n=3,3.7 \%)$. Mean full-scale intelligent quotient was $96.8 \pm 19.9$ (range, 55-136). Fourteen subjects (17.1\%) were previously treated with methylphenidate for less than one year.

The mean duration of follow-up was $1.49 \pm 0.88$ years (range, $1.00-4.48$ years). The mean daily $\mathrm{mg} / \mathrm{kg}$ dose was $1.00 \pm 0.23 \mathrm{mg} / \mathrm{kg}$ (range, $0.51-1.51 \mathrm{mg} / \mathrm{kg}$ ). The mean height and weight $\mathrm{z}$ scores at baseline were $0.28 \pm 0.90$ (range, -1.742.03 ) and $0.18 \pm 1.02$ (range, $-1.77-2.82$ ), respectively.

\section{Effects of atomoxetine on height}

Table 2 described the subjects' height at baseline and after one year of medication. Height $\mathrm{z}$ scores significantly decreased during treatment, although the $\beta$ coefficient was small ( $b=$ -0.054, $\mathrm{p}=0.024$ ) (Figure 1A). In a 9-year-old boy with a height $\mathrm{z}$ score of 0 at the start of atomoxetine treatment, height would be $0.32 \mathrm{~cm}$ less than expected after 1 year of treatment. Height $\mathrm{z}$ scores decreased during the 1 st year of medication $(\beta=-0.086$, $\mathrm{p}=0.003)$, but did not change after the 1 st year $(\beta=-0.003, \mathrm{p}=$ 0.954).

In the univariate random coefficients model, age of first dose $(p=0.108)$, gender $(p=0.526)$, baseline height $z$ score $(\mathrm{p}=0.351)$, ADHD presentation ( $\mathrm{p}=0.795$ for predominantly inattentive, $\mathrm{p}=0.109$ for predominantly hyperactive-impul-

Table 2. Comparison of height and weight at baseline and after one year of atomoxetine treatment

\begin{tabular}{lccrr}
\hline & At baseline & After one year of medication & $\mathrm{t}^{*}$ & \multicolumn{1}{c}{$\mathrm{p}^{*}$} \\
\hline Height $(\mathrm{cm})$ & $133.03 \pm 11.96$ & $137.99 \pm 12.44$ & -24.650 & $<0.001$ \\
Weight $(\mathrm{kg})$ & $32.54 \pm 11.57$ & $35.50 \pm 12.54$ & -7.510 & $<.0001$ \\
Height $(\mathrm{z})$ & $0.28 \pm 0.90$ & $0.20 \pm 0.90$ & 3.061 & 0.030 \\
Weight $(\mathrm{z})$ & $0.18 \pm 1.02$ & $0.07 \pm 1.04$ & 2.349 & 0.021 \\
\hline
\end{tabular}

*paired t test
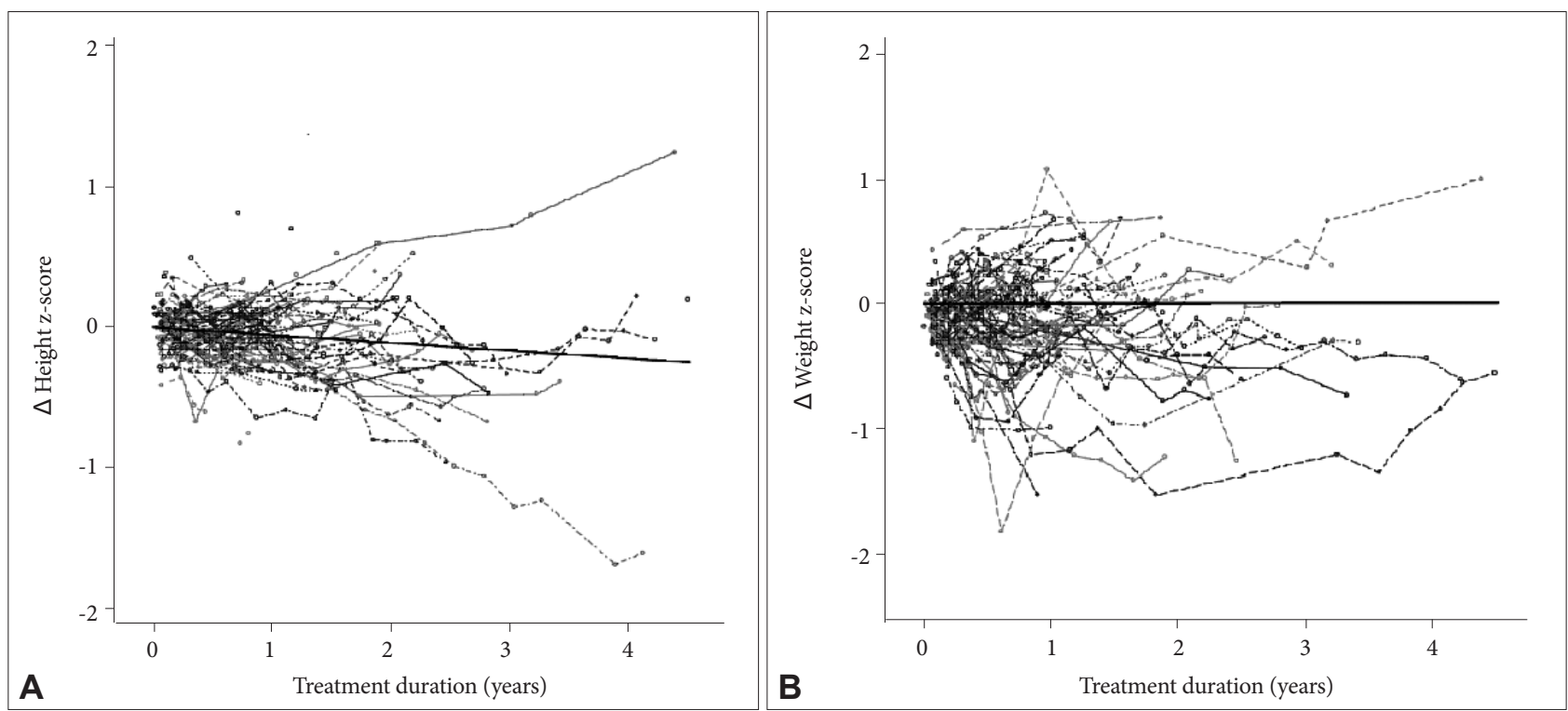

Figure 1. Changes in $\Delta$ height and $\Delta$ weight z-score during atomoxetine treatment. A: Height changes in z-score during treatment. B: Weight changes in z-score during treatment. 
sive, and $\mathrm{p}=0.598$ for combined vs. other specified ADHD), IQ $(p=0.099)$, mean daily $\mathrm{mg} / \mathrm{kg}$ atomoxetine dose $(\mathrm{p}=0.552)$, history of previous medication of methylphenidate $(\mathrm{p}=0.743)$, or comorbid diagnosis of tic ( $\mathrm{p}=0.788)$, ODD/CD $(\mathrm{p}=0.763)$, anxiety $(\mathrm{p}=0.336), \operatorname{mood}(\mathrm{p}=0.249), \mathrm{OCD}(\mathrm{p}=0.238)$, or elimination disorders $(\mathrm{p}=0.179)$ were not associated with $\Delta$ height $\mathrm{z}$ score, but comorbid ASD ( $\beta=-0.142, \mathrm{p}=0.038)$ was significantly associated with $\Delta$ height $\mathrm{z}$ score (Table 3 ).

\section{Effects of atomoxetine on weight}

Table 2 described the subjects' weight at baseline and after one year of medication. Changes of weight $\mathrm{z}$ scores was not significant during treatment period $(\beta=0.004, \mathrm{p}=0.925)$ (Figure 1B). Weight $\mathrm{z}$ scores tended to decrease during the 1 st year of medication and after the 1st year, but the changes were not significant $(\beta=-0.073, p=0.181$ for the 1 st year and $\beta=0.070, p=$ 0.208 after the 1 st year).

In the univariate random coefficients model, age of first dose $(\mathrm{p}=0.944)$, gender $(\mathrm{p}=0.969)$, baseline height $\mathrm{z}$ score $(\mathrm{p}=$
0.582 ), ADHD presentation ( $\mathrm{p}=0.928$ for predominantly inattentive, $\mathrm{p}=0.224$ for predominantly hyperactive-impulsive, and $p=0.771$ for combined vs. other specified ADHD), IQ ( $p=$ $0.479)$, mean daily $\mathrm{mg} / \mathrm{kg}$ atomoxetine dose $(\mathrm{p}=0.416)$, history of previous medication of methylphenidate $(\mathrm{p}=0.741)$, or comorbid diagnoses of tic disorder $(\mathrm{p}=0.262), \mathrm{ODD} / \mathrm{CD}(\mathrm{p}=$ $0.660)$, anxiety $(\mathrm{p}=0.264), \operatorname{ASD}(\mathrm{p}=0.831), \operatorname{mood}(\mathrm{p}=0.276)$, OCD $(p=0.472)$, or elimination disorders $(p=0.715)$ were not associated with $\Delta$ weight $\mathrm{z}$ score.

\section{DISCUSSION}

In this study, we investigated the effects of long-term treatment with atomoxetine on height and weight growth of Korean children and adolescents. There was a significant negative effect on height growth, but the growth declined due to 1 year of medication was $0.32 \mathrm{~cm}$ for a 9 year old boy with average height, and was likely not a clinically meaningful change. No significant effect on weight growth was observed in our

Table 3. Results of the univariate random coefficients model for the change in height $z$ score from the start of treatment

\begin{tabular}{|c|c|c|c|}
\hline & \multicolumn{3}{|c|}{$\Delta$ Height z score } \\
\hline & B & SE & $\mathrm{p}$ value \\
\hline Age of first dose & 0.015 & 0.009 & 0.108 \\
\hline \multicolumn{4}{|l|}{ Gender } \\
\hline Boys & 0.025 & 0.042 & 0.558 \\
\hline Girls & & (reference) & \\
\hline Baseline $\mathrm{z}$ score & -0.033 & 0.020 & 0.105 \\
\hline IQ & 0.002 & 0.001 & 0.099 \\
\hline \multicolumn{4}{|l|}{ ADHD presentation } \\
\hline Predominantly inattentive presentation & 0.02 & 0.075 & 0.795 \\
\hline Predominantly hyperactive-impulsive presentation & 0.273 & 0.168 & 0.109 \\
\hline Combined presentation & 0.039 & 0.073 & 0.598 \\
\hline Other specified ADHD & & (reference) & \\
\hline Mean daily dose (mg/kg) & -0.048 & 0.080 & 0.552 \\
\hline \multicolumn{4}{|l|}{ Previous treatment of $\mathrm{MPH}$} \\
\hline Yes & -0.015 & 0.047 & 0.743 \\
\hline No & & (reference) & \\
\hline \multicolumn{4}{|l|}{ Comorbid diagnosis } \\
\hline Tic disorder & -0.011 & 0.039 & 0.788 \\
\hline $\mathrm{ODD} / \mathrm{CD}$ & 0.013 & 0.043 & 0.763 \\
\hline Anxiety disorder & -0.046 & 0.047 & 0.336 \\
\hline ASD & -0.142 & 0.067 & 0.038 \\
\hline Mood disorder & 0.088 & 0.076 & 0.249 \\
\hline OCD & -0.088 & 0.074 & 0.238 \\
\hline Elimination disorder & 0.126 & 0.093 & 0.179 \\
\hline
\end{tabular}

ADHD: attention deficit/hyperactivity disorder, ASD: autism spectrum disorder, CD: conduct disorder, MPH: methylphenidate, OCD: obsessive compulsive disorder, ODD: oppositional defiant disorder 
study.

In our study, the effect of atomoxetine treatment on height growth deficit was significant during the $1^{\text {st }}$ year of treatment and not later. This is consistent with previous studies that concluded that negative effects on growth exist during early phases of treatment, with attenuation occurring after 18-24 month. For example, Spencer et al. ${ }^{2}$ reported that the height of ADHD children and adolescents treated with atomoxetine was significantly smaller at 12 and 18 months of treatment, but not at 24 months. Furthermore, Kratochvil et al. ${ }^{4}$ also reported that young children received atomoxetine was $2.7 \mathrm{~cm}$ smaller than expected at 24 months, and the difference occurred mostly during the first 18 months $(2.9 \mathrm{~cm}$ lower than expected). Previous studies have proposed that suppression of caloric intake related to gastrointestinal adverse events, such as nausea, vomiting, and abdominal pain could negatively affect potential growth in youths. ${ }^{11,12} \mathrm{~A}$ meta-analysis of 6- to 8 -week randomized controlled trials reported that children treated with atomoxetine commonly experience gastrointestinal adverse events. ${ }^{13}$ However, in long-term studies, the incidence of gastrointestinal adverse events appears to be concentrated within the first three months of treatment and rapidly disappeared thereafter, ${ }^{6}$ which is compatible with recovery of growth in the long term.

In our results, a small but significant growth reduction of height was observed, but no significant change in weight growth was seen. The observation period of our study may have affected these outcomes. In Spencer et al's studies, both of height and weight growth were decreased during the early phases of the treatment, with attenuation occurring afterward, but there was a difference between height and weight of time when the growth declined and recovered. The height growth reached a maximum shortfall at 18 months and weight at 15 months. Our mean observation period was 17.9 months and is similar to the period when the deficit of height growth was worst seen in Spencer et al's results, and this may have affected our results. To address this issue, longer follow-up studies are needed.

In our study, comorbid ASD was associated with the effect of atomoxetine on height growth. Most previous studies enrolled ADHD participants using DSM-IV-TR criteria, which does not allow a child with ASD to be given ADHD diagnosis, thus could not examine the influence of atomoxetine on ADHD subjects with comorbid ASD. Previous studies have reported that children with ASD are vulnerable to the gastrointestinal adverse effects of atomoxetine. ${ }^{14,15}$ Thus their growth could be more influenced by atomoxetine treatment. In this study, the sample with ASD in this study was small, and the result is non-conclusive. Further evaluation with a larger sample size is needed.
There are some limitations to consider. First, this was a retrospective chart review. Second, only subjects who were treated with atomoxetine for at least one year were included. This may have caused a selection bias. As subjects who experienced a severe growth deficits may be discontinued atomoxetine treatment before 1 year, as a result, the effects of atomoxetine on growth may be underestimated. A prospective longitudinal study that considers dropouts is needed to resolve this issue. Third, this study did not include a control group of unmedicated youths with ADHD. Fourth, this study did not consider the influence of genetic factors, such as the heights and weights of the children's parents.

This retrospective chart review suggests that atomoxetine treatment could be related to height deficits in Korean children and adolescents with ADHD, and the effects were minor and were attenuated after the $1^{\text {st }}$ year of treatment. Because of the limitations of the retrospective study design, further prospective studies are needed.

\section{Acknowledgments}

This research was supported by the Basic Science Research Program through the National Research Foundation of Korea (NRF) funded by the Korea government (Ministry of Science, ICT and Future Planning) (NRF2015R1A1A3A04001349).

\section{REFERENCES}

1. Hammerness P, McCarthy K, Mancuso E, Gendron C, Geller D. Atomoxetine for the treatment of attention-deficit/hyperactivity disorder in children and adolescents: a review. Neuropsychiatr Dis Treat 2009;5: 215-226.

2. Spencer TJ, Kratochvil CJ, Sangal RB, Saylor KE, Bailey CE, Dunn DW, et al. Effects of atomoxetine on growth in children with attentiondeficit/hyperactivity disorder following up to five years of treatment. J Child Adolesc Psychopharmacol 2007;17:689-699.

3. Spencer TJ, Newcorn JH, Kratochvil CJ, Ruff D, Michelson D, Biederman J. Effects of atomoxetine on growth after 2-year treatment among pediatric patients with attention-deficit/hyperactivity disorder. Pediatrics 2005;116:e74-e80.

4. Kratochvil CJ, Wilens TE, Greenhill LL, Gao H, Baker KD, Feldman $\mathrm{PD}$, et al. Effects of long-term atomoxetine treatment for young children with attention-deficit/hyperactivity disorder. J Am Acad Child Adolesc Psychiatry 2006;45:919-927.

5. Donnelly C, Bangs M, Trzepacz P, Jin L, Zhang S, Witte MM, et al. Safety and tolerability of atomoxetine over 3 to 4 years in children and adolescents with ADHD. J Am Acad Child Adolesc Psychiatry 2009; 48:176-185.

6. Wilens TE, Newcorn JH, Kratochvil CJ, Gao H, Thomason CK, Rogers $\mathrm{AK}$, et al. Long-term atomoxetine treatment in adolescents with attention-deficit/hyperactivity disorder. J Pediatr 2006;149:112-119.

7. Michelson D, Read HA, Ruff DD, Witcher J, Zhang S, McCracken J. CYP2D6 and clinical response to atomoxetine in children and adolescents with ADHD. J Am Acad Child Adolesc Psychiatry 2007;46:242251.

8. Kitada M. Genetic polymorphism of cytochrome P450 enzymes in Asian populations: focus on CYP2D6. Int J Clin Pharmacol Res 2002; 23:31-35.

9. Liang B, Zhan Y, Wang Y, Gu E, Dai D, Cai J, et al. Effect of 24 Cytochrome P450 2D6 variants found in the Chinese population on atom- 
oxetine metabolism in vitro. Pharmacology 2016;97:78-83.

10. Korea Center for Disease Control and Prevention. 2007 Korean Children and Adolescents Growth Standard. Cheongwon: Korean Pediatric Society, 2008. Available at: http://www.cdc.go.kr/. Accessed September 1, 2017.

11. Reed VA, Buitelaar JK, Anand E, Day KA, Treuer T, Upadhyaya HP, et al. The safety of atomoxetine for the treatment of children and adolescents with attention-deficit/hyperactivity disorder: a comprehensive review of over a decade of research. CNS Drugs 2016;30:603-628.

12. Vitiello B. Understanding the risk of using medications for attention deficit hyperactivity disorder with respect to physical growth and cardiovascular function. Child Adolesc Psychiatr Clin N Am 2008;17:459474.
13. Wilens T, Kratochvil C, Newcorn J, Gao H. Do children and adolescents with ADHD respond differently to atomoxetine? J Am Acad Child Adolesc Psychiatry 2006;45:149-157.

14. Troost PW, Steenhuis MP, Tuynman-Qua HG, Kalverdijk LJ, Buitelaar JK, Minderaa RB, et al. Atomoxetine for Attention-Deficit/Hyperactivity Disorder Symptoms in Children with Pervasive Developmental Disorders: APilot Study. J Child Adolesc Psychopharmacol 2006;16:611619.

15. Valicenti-McDermott M, McVicar K, Rapin I, Wershil BK, Cohen H, Shinnar S. Frequency of gastrointestinal symptoms in children with autistic spectrum disorders and association with family history of autoimmune disease. J Dev Behav Pediatr 2006;27(2 Suppl):S128-S136. 